\title{
Effects of adding load to the gait of children with cerebral palsy: a three-case report
} Efeitos da adição de carga na marcha de crianças com paralisia cerebral: relato de três casos

Efectos de la adición de carga sobre la marcha de niños con parálisis cerebral: relato de tres casos Camila Rocha Simão', Élida Rayanne Viana Pinheiro Galvão², Débora Oliveira da Silveira Fonseca², Dayse Aleixo Bezerra ${ }^{3}$, Amanda Capistrano de Andrade ${ }^{3}$, Ana Raquel Rodrigues Lindquist ${ }^{1,2}$

\begin{abstract}
I Our purpose in this study was to analyze the immediate effects of locomotor gait training with different loads on a treadmill on the kinematic parameters of gait in children with Spastic Hemiparetic Cerebral Palsy (SHCP), as well as investigating which load prompted the most adequate motor responses to promote the propulsion of the Paretic Lower Limb (PLL). This case report included 3 children of both sexes, aged 8-12 years. The children walked on the treadmill with loads on their ankles that corresponded to 40,50 and $60 \%$ of the weight of the Lower Limb (LL), on 3 different non-consecutive days. The kinematic parameters were assessed during the pretraining phase $\left(\mathrm{PT}_{\mathrm{PH}}\right)$ and immediately after training $\left(\mathrm{PH}_{\mathrm{P}}\right)$. The spatiotemporal variables did not change immediately after gait training with the aforementioned loads. On the other hand, we observed wider joint angles in the hip and knee during the swing phase immediately after training, especially with a load of $60 \%$ of the weight of the lower limb. These findings indicate that the $60 \%$ load is the most appropriate to prompt immediate changes in the joint kinematics of the PLL. These alterations can be important in improving propulsion during the swing phase of gait in children with SHCP.

Keywords I Cerebral Palsy; Rehabilitation; Gait; Weight-Bearing.
\end{abstract}

RESUMO I O objetivo deste estudo foi analisar os efeitos imediatos do treino locomotor na esteira com diferentes cargas, sobre os parâmetros cinemáticos da marcha de crianças com Paralisia Cerebral Hemiparética Espástica (PCHE), e investigar qual carga promove repostas motoras mais adequadas para favorecer a propulsão do Membro Inferior Parético (MIP). Participaram deste relato de caso 3 crianças de ambos os sexos, com idades de 8-12 anos. As crianças realizaram treino na esteira com carga nos tornozelos equivalentes a 40, 50 e 60\% do peso do Membro Inferior (MI), em 3 dias diferentes e não consecutivos. Os parâmetros cinemáticos foram avaliados nas fases prétreinamento $\left(F_{\mathrm{PT}}\right)$ e imediatamente após o treino $\left(F_{\text {P }}\right.$. As variáveis espaço-temporais não sofreram alterações imediatamente após o treino de marcha com carga. Por outro lado, foi observado aumento dos ângulos articulares de quadril e joelho durante a fase de balanço imediatamente após o treino, principalmente com carga de 60\% do peso do membro inferior. Estes achados indicam que a carga de $60 \%$ seja a mais apropriada para solicitar alterações imediatas na cinemática articular do MIP. Tais alterações podem ser importantes para favorecer a propulsão durante a fase de balanço da marcha de crianças com PCHE.

Descritores | Paralisia Cerebral; Reabilitação; Marcha; Suporte de Carga.

RESUMEN I El objetivo de este estudio fue analizar los efectos inmediatos del entrenamiento locomotor en la estera con diferentes cargas, sobre los parámetros cinemáticos de la marcha de niños con parálisis cerebral hemipléjica

Study conducted at the Laboratory for Intervention and Analysis of Movement (LIAM) of the Department of Physical Therapy at Universidade Federal do Rio Grande do Norte (UFRN) - Natal (RN), Brazil.

'Graduate Program in Physical Therapy from UFRN - Natal (RN), Brazil.

${ }^{2}$ Physical Therapy course at UFRN, Natal (RN) - Brazil.

${ }^{3}$ Specialist in Neurological Physical Therapy, UFRN - Natal (RN), Brazil. 
espástica (PCHE), e investigar cómo la carga promueve respuestas motoras más adecuadas para favorecer la propulsión del Miembro Inferior Parético (MIP). Participaron de este caso, 3 niños de ambos sexos, con edades de 8-12 años. Los niños realizaron entrenamiento en la estera rodante con carga en los tobillos equivalente a 40, 50 y $60 \%$ del peso de la miembro (MI), en 3 días distintos y no consecutivos. Los parámetros cinemáticos fueron evaluados en las fases de pre entrenamiento (FPT), e inmediatamente después del entrenamiento $(\mathrm{FI})$. Las variables espacio-temporales no cambiaron inmediatamente después del ejercicio de marcha con carga.
Sin embargo, fue observado aumento de los ángulos articulares de la cadera y la rodilla durante la fase de balanceo inmediatamente después del entrenamiento, especialmente con carga de 60\% del peso de la extremidad inferior. Estos resultados indican que la carga de 60\% es la más apropiada para solicitar cambios inmediatos en la cinemática articular del MIP. Tales cambios pueden ser importantes para fomentar la propulsión durante la fase de balanceo de la marcha de niños con PCHE.

Palabras clave I Parálisis Cerebral; Rehabilitación; Marcha; Soporte de Carga.

\section{INTRODUCTION}

Children with Spastic Hemiparetic Cerebral Palsy (SHCP) present gait patterns characterized by predictable kinematic and kinetic alterations ${ }^{1,2}$, such as slow progression speed, shorter step length, larger base of support ${ }^{3}$, and longer duration of the phase of support on the non-paretic $\mathrm{leg}^{4}$. Decreased dorsiflexion during the swing phase and lower amplitudes of knee and hip flexion and extension are also observed ${ }^{1}$. Along with the diminished capability of the flexor plantar muscles to generate propulsion force, these kinematic alterations result in inefficiencies to lift an individual's foot off the surface $e^{5,6}$, thus leading to a pattern of "dragging" the Paretic Lower Limb (PLL) during propulsion ${ }^{7}$.

With the purpose of improving the gait efficiency of children with SHCP, techniques of intervention have been suggested and utilized to increase the generation of force by specific muscle groups at the ideal time within the gait cycle. Considering that changes at the moment of force generation can favor the system's dynamic reorganization and promote alterations in motor behavior ${ }^{5}$, it is suggested that the physical therapy treatments administered to the gait of children with SHCP must be based on muscle strengthening and aimed at producing hip flexion strength ${ }^{7}$.

Some authors have investigated adaptive changes in human locomotor behavior in response to external perturbations and showed that interferences with the system weaken the previous stability of the motor pattern and increase the possibilities of an individual modifying motor strategies in order to perform the same task more efficiently ${ }^{8-10}$. The literature on the topic describes that the imposition of resistance during the swing phase of gait — by adding load onto the Lower Limb (LL) results in compensatory motor responses in the gait of healthy babies and adults, and of adults with neurological pathologies ${ }^{11-18}$. The main locomotor adjustments presented by these populations immediately after the removal of the imposed resistance are increases in gait speed ${ }^{15,16,18}$, flexor muscle torque ${ }^{14,17}$, flexor muscle activity ${ }^{11,13,14,17}$ and height of steps ${ }^{11,13,14}$, as well as an increase in the angle of hip and knee flexion during the swing phase $\mathrm{e}^{11,13,15}$.

Considering that adding load onto the LL overloads flexor muscles during the swing phase, resulting in increased activities and amplitudes of hip and knee flexion during the swing phase of human gait ${ }^{11-17}$, we hypothesized that the presence of such locomotor adjustments would be adequate to improve the propulsion efficiency of the PLL during the swing phase of children with SHCP.

We did not find, in the current literature, clinical studies that investigated the locomotor behavior of children with SHCP in response to training with addition of load to the ankles. It is not known whether this population is able to adapt locomotor patterns and what are the motor strategies adopted by them. Moreover, there is no consensus regarding the most adequate load to be used in order to favor PLL propulsion during swing phase. Thus, in this study, we proposed to observe the behavior of kinematic variables in children with SHCP immediately after gait training on a treadmill with loads on their ankles, in addition to investigating which percentage is more appropriate to enable efficient PLL propulsion.

\section{METHODOLOGY}

\section{Participants}

This is a case report in which the participants were 3 children with SHCP who were 8, 9, and 12 years of 
age, of both sexes, and able to walk without aid devices. Their clinical and demographic characteristics are displayed on Table 1 .

This study was approved by UFRN's Ethics Committee (report number 76.519), and the parents and/or legal guardians signed the Informed Consent.

\section{Measurement instruments}

We used the D and E dimensions of the Gross Motor Function Classification System (GMFCS) to characterize and assess the children's functional performances. This scale describes the functional abilities of children with cerebral palsy in five levels ${ }^{19}$. The children included in this study were classified in Level I (independent gait, without restrictions).

In order to characterize and assess the participants' gross motor function, we examined the $\mathrm{D}$ and $\mathrm{E}$ dimensions of the Gross Motor Function Measure (GMFM66), a standardized test that quantifies the gross motor function of children with neuromotor disorders. In this study we assessed mobility, maintenance and transition of postures based on the $\mathrm{D}$ and $\mathrm{E}$ dimensions of the GMFM-66 test ${ }^{20,21}$.

The spasticity was assessed through the Modified Ashworth Scale, which consists of a subjective assessment of the degree of muscle resistance during passive joint movement, where a score 0 corresponds to the absence of increase in muscle tonus, and 4 represents rigid joints in positions of rest ${ }^{22}$. In the present study we assessed the ischiotibial, gastrocnemius, and soleus muscles of the PLL during movements of knee extension and ankle dorsiflexion with the knee extended and flexed, respectively.

The assessment of gait was performed by the Qualysis - ProReflex MCU Movement Analysis System, a video-based photogrammetry system that reconstructs passive reflective markers located in specific bone prominences in three dimensions (3D). It is composed of eight cameras that emit infrared light, captured and reflected by the passive markers. The data were captured by the Qualisys Track Manager 1.6.O.x - QTM acquisition software at a frequency of $120 \mathrm{~Hz}$ and exported to the Visual $3 D$ processing software for the reconstruction of the segments and creation of the biomechanical model.

\section{Assessment procedures}

Firstly, we obtained information about the diagnoses and anthropometric characteristics of the children, who were classified by the GMFCS. We then applied the D and E dimensions of the GMFM-66 test, in addition to assessing the spasticity degree of the lower limbs in order to characterize the sample. In accordance with the children's age, we determined the mass of the LL based on the calculation proposed by Jensen ${ }^{23}$, through which we determined the masses of the foot $((0,00015 x$ xage $+0,0187)$, leg $(0,00122$ xage $+0,3809)$ and thigh $(0,00364 x i d a-$ $\mathrm{de}+0,06634)$. Based on this calculation, we defined the loads (corresponding to 40, 50 and $60 \%$ of the LL mass) that were utilized in the treadmill training ${ }^{23}$.

The collection of the kinematic data was conducted on three different and non-consecutive days, in two moments - static and dynamic collection. In order to carry out the kinemetry, passive markers were positioned bilaterally on specific bone prominences, namely iliac crests, greater trochanter of the femur, lateral and medial epicondyles of the femur, lateral and medial malleolus, heads of the first and fifth metatarsal bones, and base of the calcaneus. Tracking markers (Cluster) were positioned to identify the trajectories of each segment.

For the static collection, the children remained in the orthostatic position at the center of the system's active area for three seconds. The dynamic collection, conducted as the children walked on the electric treadmill Movement ${ }^{\circledR}$ CardioFitPlus, was divided in two phases: 1) pre-training $\left(\mathrm{PT}_{\mathrm{PH}}\right)$, in which we obtained kinematic data about the gait on the treadmill that referred to the baseline; 2) immediately after training $\left(\mathrm{PH}_{\mathrm{I}}\right)$, when we obtained kinematic data about the gait on the treadmill immediately after the end of the training with loads attached to the participants' ankles. At the last minute of both phases of the dynamic collection, we had obtained the kinematic data of ten cycles (Figure 1).

Table 1. Clinical and anthropometric characteristics of the sample, and loads used in the three experimental conditions

\begin{tabular}{|c|c|c|c|c|c|c|c|c|c|c|c|c|c|}
\hline Child & GMFCS & Sex & $\begin{array}{c}\text { Age } \\
\text { (years) }\end{array}$ & $\begin{array}{l}\text { Compromised } \\
\text { hemibody }\end{array}$ & $\begin{array}{l}\text { Weight } \\
\text { (kg) }\end{array}$ & $\begin{array}{l}\text { Height } \\
(\mathrm{m})\end{array}$ & $\begin{array}{l}40 \% \\
\text { Load }\end{array}$ & $\begin{array}{l}50 \% \\
\text { Load }\end{array}$ & $\begin{array}{l}60 \% \\
\text { Load }\end{array}$ & $\begin{array}{l}\text { Orthosis } \\
\text { (AFO) }\end{array}$ & GMFM & SDTSP & SDITMP \\
\hline 1 & I & M & 12 & Right & 39,4 & 1,55 & $2,800 \mathrm{~kg}$ & $3,500 \mathrm{~kg}$ & $4,200 \mathrm{~kg}$ & No & $99,3 \%$ & 1 & +1 \\
\hline 2 & I & $\mathrm{F}$ & 8 & Left & 29,9 & 1,30 & $1,600 \mathrm{~kg}$ & $2,000 \mathrm{~kg}$ & $2,500 \mathrm{~kg}$ & No & $97,3 \%$ & 1 & 1 \\
\hline 3 & 1 & $M$ & 9 & Left & 46,2 & 1,23 & $2,700 \mathrm{~kg}$ & $3,400 \mathrm{~kg}$ & $4,100 \mathrm{~kg}$ & Yes & $84,6 \%$ & 1 & +1 \\
\hline
\end{tabular}

M: male; F: female; GMFCS: Gross Motor Function Classification System; AFO: Ankle Foot Orthoses; GMFM: Gross Motor Function Measure; SDTSP: Spasticity Degree of the Triceps Surae of the Paretic Limb; SDITMP: Spasticity Degree of the Ischiotibial Muscles of the Paretic Limb 


\section{Experimental protocol}

The three children performed the training protocol on the treadmill using loads of 40,50 and $60 \%$ of the LL weight, attached to their ankles bilaterally with shin guards. This training was conducted on three different and non-consecutive days, and the order of use of the percentages proposed was random and based on a previous draw. The collection of the kinematic data was carried out concomitantly to the training for the three experimental conditions.

The children walked at their maximum comfortable speed, defined at the moment they familiarized themselves with the treadmill. One of the children routinely used a rigid orthosis on the ankle, and kept using it during the conduction of the experimental protocol (Figure 2).

\section{Data reduction}

The data were captured by the software $Q T M$ and processed by the software Visual3D, which creates a system of coordinates for each segment and determines position and orientation based on anatomic markers. Drawing on the anatomic and tracking markers, a biomechanical model was constructed and the angles of
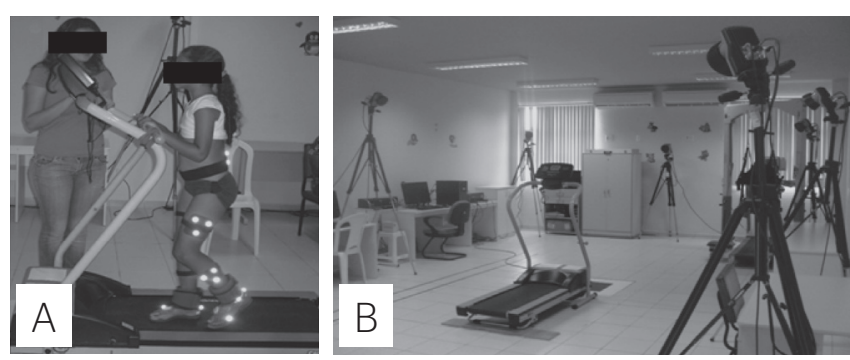

Figure 1. (A) Positioning of the load and passive markers during training on the treadmill; (B) Disposition of the cameras around the treadmill for the collection of kinematic data joint movement were obtained according to the sequence proposed by Cardan ${ }^{24}$.

We investigated the following spatiotemporal variables: cadence, double support, length of step, time length of support, and time length of the swing phase of the PLL. Regarding angular variables, we investigated angular movements in the hip and knee sagittal plane. For both PLL joints, we investigated maximum extension during support, maximum flexion during balance, as well as flexion and extension width, obtained through the subtraction of the maximum value by the minimum value achieved during the entire cycle.

\section{RESULTS}

We proceed to present the averages of the kinematic parameters of the three children evaluated with the use of the three load percentages, as follows:

\section{Spatiotemporal variables}

Table 2 displays the behavior of the spatial and temporal variables in response to the gait training on the treadmill with the three percentages of load during phases $\mathrm{PT}_{\mathrm{PH}}$ and $\mathrm{PH}_{\mathrm{T}}$. The alterations observed immediately after the removal of the load were not significant (Table 2).

\section{Angular variables}

Table 3 shows that, immediately after the removal of the load, the gait training on the treadmill with a load on the LL promoted alterations in the joint kinematics of the hip and paretic knee during the swing phase. Furthermore, we observed that $60 \%$ of the LL weight led to a more expressive increase in these variables (Table 3 ).

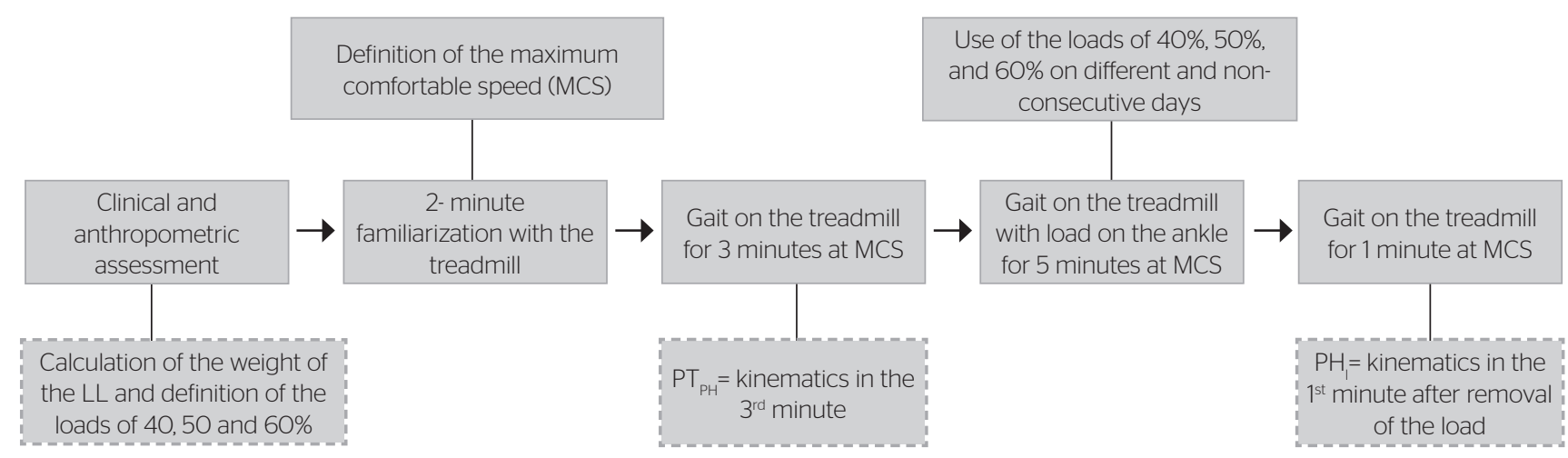

Figure 2. Phases of collection of dynamic data, and training protocol 
Table 2. Average of the spatiotemporal variables for the three experimental conditions in both phases of assessment

\begin{tabular}{|c|c|c|c|c|c|c|}
\hline \multirow[b]{2}{*}{ Spatiotemporal variables } & \multicolumn{2}{|c|}{$40 \%$ Load } & \multicolumn{2}{|c|}{$50 \%$ Load } & \multicolumn{2}{|c|}{$60 \%$ Load } \\
\hline & $\begin{array}{c}\mathrm{PT}_{\mathrm{PH}} \\
\text { Mean } \pm \mathrm{SD}\end{array}$ & $\begin{array}{c}\mathrm{PH}_{1} \\
\text { Mean } \pm \mathrm{SD}\end{array}$ & $\begin{array}{c}\mathrm{PT}_{\mathrm{PH}} \\
\text { Mean } \pm \mathrm{SD}\end{array}$ & $\begin{array}{c}\mathrm{PH}_{1} \\
\text { Mean } \pm S D\end{array}$ & $\begin{array}{c}\mathrm{PT}_{\mathrm{PH}} \\
\text { Mean } \pm \mathrm{SD}\end{array}$ & $\begin{array}{c}\mathrm{PH}_{1} \\
\text { Mean } \pm \mathrm{SD}\end{array}$ \\
\hline Speed (m/s) & $0.37 \pm 0.04$ & $0.37 \pm 0.03$ & $0.37 \pm 0.02$ & $0.37 \pm 0.03$ & $0.37 \pm 0.03$ & $0.37 \pm 0.03$ \\
\hline Cadence (steps/min) & $115.57 \pm 53.97$ & $124.6 \pm 44.08$ & $108.21 \pm 26.71$ & $111.54 \pm 29.07$ & $109.87 \pm 57.81$ & $110.71 \pm 27.82$ \\
\hline Step length P (m) & $0.36 \pm 0.06$ & $0.32 \pm 0.03$ & $0.37 \pm 0.01$ & $0.33 \pm 0.00$ & $0.33 \pm 0.01$ & $0.31 \pm 0.01$ \\
\hline Support time P (\%) & $0.34 \pm 0.03$ & $0.35 \pm 0.02$ & $0.35 \pm 0.02$ & $0.33 \pm 0.01$ & $0.34 \pm 0.006$ & $0.33 \pm 0.03$ \\
\hline Balance time P (\%) & $0.16 \pm 0.02$ & $0.15 \pm 0.01$ & $0.16 \pm 0.02$ & $0.16 \pm 0.01$ & $0.17 \pm 0.01$ & $0.17 \pm 0.03$ \\
\hline Double support (\%) & $0.21 \pm 0.03$ & $0.21 \pm 0.03$ & $0.21 \pm 0.02$ & $0.19 \pm 0.02$ & $0.19 \pm 0.02$ & $0.19 \pm 0.04$ \\
\hline
\end{tabular}

$\mathrm{PT}_{\text {PH: }}$ : pre-training phase; $\mathrm{PH}_{\mathrm{F}}$ phase immediately after the training with load; Av: average; $\mathrm{SD}$ : standard deviation; $\mathrm{P}$ : paretic limb

Table 3. Average of the angular variables for the three experimental conditions in both phases of assessment

\begin{tabular}{|c|c|c|c|c|c|c|}
\hline \multirow[b]{2}{*}{ Angular variables } & \multicolumn{2}{|c|}{$40 \%$ Load } & \multicolumn{2}{|c|}{$50 \%$ Load } & \multicolumn{2}{|c|}{$60 \%$ Load } \\
\hline & $\begin{array}{c}\mathrm{PT}_{\mathrm{PH}} \\
\text { Mean } \pm \mathrm{SD}\end{array}$ & $\begin{array}{c}\mathrm{PH}_{1} \\
\text { Mean } \pm \mathrm{SD}\end{array}$ & $\begin{array}{c}\mathrm{PT}_{\mathrm{PH}} \\
\mathrm{Mean} \pm \mathrm{SD}\end{array}$ & $\begin{array}{c}\mathrm{PH}_{1} \\
\text { Mean } \pm \mathrm{SD}\end{array}$ & $\begin{array}{c}\mathrm{PT}_{\mathrm{PH}} \\
\text { Mean } \pm \mathrm{SD}\end{array}$ & $\begin{array}{c}\mathrm{PH}_{1} \\
\text { Mean } \pm \mathrm{SD}\end{array}$ \\
\hline \multicolumn{7}{|l|}{ P Hip } \\
\hline Maximum flexion - swing & $71.80 \pm 3.88$ & $72.09 \pm 6.05$ & $79.51 \pm 4.38$ & $77.56 \pm 6.12$ & $68.67 \pm 0.96$ & $75.44 \pm 7.96$ \\
\hline Maximum extension -support & $34.47 \pm 14.27$ & $35.96 \pm 15.91$ & $35.31 \pm 13.67$ & $35.45 \pm 14.72$ & $22.20 \pm 6.97$ & $25.17 \pm 0.39$ \\
\hline Flexion and extension amplitude & $37.33 \pm 12.73$ & $36.13 \pm 10.45$ & $44.19 \pm 9.79$ & $42.11 \pm 8.59$ & $46.47 \pm 7.16$ & $50.27 \pm 1.87$ \\
\hline \multicolumn{7}{|l|}{ P Knee } \\
\hline Maximum flexion - swing & $81.69 \pm 4.64$ & $83.73 \pm 5.20$ & $84.99 \pm 0.48$ & $86.26 \pm 1.60$ & $79.28 \pm 8.84$ & $85.24 \pm 8.01$ \\
\hline Maximum extension -support & $23.13 \pm 5.21$ & $25.79 \pm 11.16$ & $22.93 \pm 6.50$ & $24.7 \pm 8.33$ & $20.75 \pm 13.79$ & $23.50 \pm 9.65$ \\
\hline Flexion and extension amplitude & $58.56 \pm 5.85$ & $57.94 \pm 7.70$ & $62.05 \pm 6.04$ & $61.56 \pm 7.06$ & $58.53 \pm 7.13$ & $61.73 \pm 8.70$ \\
\hline
\end{tabular}

$\mathrm{PT}_{\text {PH: }}$ : pre-training phase; $\mathrm{PH}_{\text {i }}$ phase immediately after the training with load; SD: standard deviation; P: paretic limb

\section{DISCUSSION}

Adding a load to the ankles of children with SHCP during training on a treadmill is an unprecedented proposal for this population. It is based on concepts relating to possible mechanical and neuromuscular adjustments that can be employed as strategies for locomotor adaptation. The results of this study showed that the children with SHCP presented a tendency to modify the joint kinematics in the LL during the swing phase, thus suggesting an ability to display immediate locomotor adaptations in response to the addition of load.

Upon comparing the angular variables before $\left(\mathrm{PT}_{\mathrm{PH}}\right)$ and immediately after the gait training $\left(\mathrm{PH}_{\mathrm{I}}\right)$, we noticed that $60 \%$ of the $L L$ weight promoted a more pronounced increase in the angular variables of hip and knee flexion, thus resulting in a multi-joint motor strategy in response to the resistance imposed during the swing phase. This strategy has also been observed in healthy individuals in response to external perturbations through increasing the height of the trajectory of the foot during the swing phase. Moreover, a strong correlation was observed between the amount of load added and the activation of hip flexor muscles ${ }^{13}$.

It is suggested that physical therapy treatments for children with SHCP must be directed toward the gain of muscle strength in the hip flexors ${ }^{6,25}$ with the purpose of improving gait efficiency ${ }^{5,25}$. The promotion and facilitation of wider angles of hip and knee flexion of the PLL during the swing phase are considered to be important compensatory strategies for this population to perform the task of walking and ensuring foot progression ${ }^{25}$. Considering that adding a load of $60 \%$ of the weight of the LL to the participants' ankles during gait training resulted in locomotor adjustments that had the purpose of favoring the propulsion of the PLL by means of a more accentuated flexion of the hip and knee during the swing phase, we suggest that this training proposal can be an appropriate tool to improve gait efficiency in this population.

Adding load to the ankles imposes resistance during the swing phase, which results in a greater activation of the flexor muscles of the $\mathrm{LL}^{11,17}$. This response can be considered a strategy of neuromotor adaptation mediated by feedback mechanisms that occur due to changes in proprioceptive input during gait with load $\mathrm{d}^{14,17,26}$. Immediately after the removal of this perturbation, an increase in the flexor activity of the LL persists for some time ${ }^{11,13,14}$, possibly due to anticipatory motor commands that are formed so that it can adapt to the new task demanded, in preparation for the coming perturbation $^{11,17,26}$. The verification of this capability to adjust to 
a load alteration and the response pattern presented during $\mathrm{PH}_{\mathrm{I}}$ by the children in this study suggest that motor commands in children with SHCP can be adjusted in response to additional weight placed on the $\mathrm{LL}^{17}$.

Upon comparing the spatiotemporal parameters obtained in the three experimental conditions (40, 50 , and $60 \%$ of the weight of the LL) during both assessment phases $\left(\mathrm{PT}_{\mathrm{PH}}\right.$ and $\left.\mathrm{PH}_{\mathrm{I}}\right)$, we observed that these parameters tend to not suffer any alterations immediately following gait training on a treadmill with the loads proposed, a fact justified by the use of the treadmill, which sets constant rhythm and speed $^{14}$. As gait speed directly influences spatial and temporal parameters ${ }^{2}$, the steady maintenance of its values, in all phases and experimental conditions, may have influenced our findings.

With the purpose of evidencing the behavior of locomotor adjustments in children with SHCP as an immediate response to the addition of a load of $60 \%$, we suggest the conduction of studies with larger samples, as a sample composed of 3 children is not enough to demonstrate the significance of the results obtained, and it is, therefore, a limitation of this study.

\section{FUTURE STUDIES}

The authors of the present study intend to investigate, in the future, the immediate effects of training on a treadmill with an added load of $60 \%$ of the LL's weight in a more representative sample of children with SHCP. We consider it important to proceed with this study by analyzing whether an increase in hip and knee flexion in the PLL during the swing phase of gait on a treadmill occurs in a significant manner in this group, and whether these adaptations can be transferred to gait on the ground after the conduction of a longitudinal training protocol.

\section{CONCLUSION}

The children with SHCP demonstrated capability of locomotor adaptation by increasing the PLL's hip and knee flexion during the swing phase in response to the addition of load to the lower limbs during gait on a treadmill. These kinematic alterations were more expressive immediately after the training with a load of
$60 \%$ of the LL's weight, which suggests that this percentage is the most adequate to prompt locomotor responses that facilitate the PLL's propulsion during the swing phase of gait.

\section{REFERENCES}

1. Rodda J, Graham HK. Classification of gait patterns in spastic hemiplegia and spastic diplegia: a basis for a management algorithm. Eur J Neurol. 2001;8(Suppl5):98-108.

2. Winters TF, Gage JR, Hicks R. Gait patterns in spastic hemiplegia in children and young adults. J Bone Joint Surg Am. 1987;69(3):437-41.

3. Galli M, Cimolin V, Rigold C, Tenore N, Albertini G. Gait patterns in hemiplegic children with cerebral palsy: comparison of right and left hemiplegia. Res Dev Disabil. 2010;31(6):1340-5.

4. Cimolin V, Galli M, Tenore N, Albertini G, Crivellini M. Gait strategy of uninvolved limb in children with spastic hemiplegia. Eura Medicophys. 2007:43(3):303-10.

5. Fonseca ST, Holt KG, Saltzman E, Fetters L. A dynamical model of locomotion in spastic hemiplegic cerebral palsy: influence of walking speed. Clin Biomech (Bristol, Avon). 2001;16(9):793-805.

6. Riad J, Haglund-Akerlind Y, Miller F. Power generation in children with spastic hemiplegic cerebral palsy. Gait Posture. 2008;27(4):641-7.

7. Perry J. Análise de Marcha: Marcha Patológica. Barueri: Manole; 2005.

8. Kamm K, Thelen E, Jensen JL. A dynamical systems approach to motor development. Phys Ther. 1990;70(12):763-75.

9. Haim SB, Harries N, Belokopytov M, Lahat E, Kaplanski J. Random Perturbation: A potential aid in treatment of children with cerebral palsy. Disabil Rehabil. 2008;30(19):1420-8.

10. Scholz JP. Dynamic Pattern Theory - Some implications for therapeutics. Phys Ther. 1990;70(12):827-43.

11. Lam T, Wolstenholme C, Yang JF. How do infants adapt to loading of the limb during the swing phase of stepping? J Neurophysiol. 2003;89(4):1920-8.

12. Patchay S, Gahéry Y. Effect of asymmetrical limb loading on early postural adjustments associated with gait initiation in young health adults. Gait Posture. 2003;18(1):85-94.

13. Houldin A, Luttin K, Lam T. Locomotor adaptions and aftereffects to resistance during walking in individuals with spinal cord injury. J Neurophysiol. 2011:106(1):247-58

14. Lam T, Wirz M, Lünenburger L, Dietz V. Swing phase resistance enhances flexor muscle activity during treadmill locomotion in incomplete spinal cord injury. Neurorehabil Neural Repair. 2008;22(5)438-46

15. Regnaux JP, Pradon D, Roche N, Robertson J, Bussel B, Dobkin B. Effects of loading the unaffected limb for one session of locomotor training on laboratory measures of gait in stroke. Clin Biomech (Bristo, Avon). 2008:23(6):762-8.

16. Kollen B, Rietberg M, Kwakkel G, Emmelot K. Effects of overloading of the lower hemiparetic extremity on walking speed in chronic stroke patient: a pilot study. NeuroRehabilitation. 2000;14(3):159-64.

17. Noble J, Prentice S. Adaptation to unilateral change in lower limb mechanical properties during human walking. Exp Brain Res. 2006;169(4):482-95. 
18. Yen SC, Schmit BD, Landry JM, Roth H, Wu M. Locomotor adaptation to resistance during treadmill training transfers to overground walking in human SCI. Exp Brain Res. 2012; 216(3): 473-82.

19. Palisano R, Rosenbaum P, Walter S, Russel D, Wood E, Galuppi B. Development and reliability of a system to classify gross motor function in children with cerebral palsy. Dev Med Child Neurol. 1997;39(4):214-23.

20. Russel DJ, Avery LM, Rosembaum P, Raina PS, Walter SD, Palisano RJ. Improved scaling of the Gross Motor Function Measure for children with cerebral palsy: Evidence of reliability and validity. Phys Ther. 2000; 80(9): 873-85.

21. Russell DJ, Rosenbaum P, Gowland C, Hardy S, Lane M, Plews N et al. Gross Motor Function Measure (GMFM - 66 \& GMFM - 88) User's Manual. Ed. Hamilton, Ontario, Canada: Mac Keith Press; 2002.
22. Scholtes VAB, Becher JG, Beelen A, Lankhorst GJ. Clinical assessment of spasticity in children with cerebral palsy: a critical review of available instruments. Dev Med Child Neurol. 2006; 48(1):64-73.

23. Jensen RK. Body segment mass, radius and radius of gyration proportions of children. J Biomech. 1986;19(5):359-68

24. Cole GK, Nigg BM, Ronsky JL, Yeadon MR. Application of the joint coordinate system to three-dimensional joint attitude and movement representation: a standardization proposal. J Biomech Eng. 1993;115(4A):344-9.

25. Olney SJ, Macphail HA, Hedden DM, Boyce WF. Work and power in hemiplegic cerebral palsy gait. Phys Ther. 1990;70(7):431-8.

26. Lam T, Andreschitz M, Dietz V. Contribution of feedback e feedforward strategies to locomotor adaptions. J Neurophysiol. 2006;95(2):766-73. 